HARRAN ÜNIVERSITESI MÜHENDISLIK DERGisi

HARRAN UNIVERSITY JOURNAL OF ENGINEERING

e-ISSN: 2528-8733

\section{HARRAN ÜNIVERSITESİ MÜHENDİSLİK DERGİSI}

HARRAN UNIVERSITY JOURNAL of ENGINEERING

e-ISSN: 2528-8733 (ONLINE)

URL: http://dergipark.gov.tr/humder

Mono ve Multi-split Klima Sistemlerinin Ömür Boyu Maliyet Analizi

Life Cycle Cost Analysis of Multi and Mono-split Air Conditioning Systems

Yazar(lar) (Author(s)): Emrah KARA', Mehmet Azmi AKTACiR', Mehmet KUŞ ${ }^{3}$

${ }^{1}$ ORCID ID: 0000-0002-3096-8608

${ }^{2}$ ORCID ID: 0000-0003-2345-7815

${ }^{3}$ ORCID ID: 0000-0003-2215-9250

Bu makaleye şu şekilde atıfta bulunabilirsiniz (To cite to this article): Kara E., Aktacir M.A., Kuş M., "Mono ve Multi-split Klima Sistemlerinin Ömür Boyu Maliyet Analizi", Harran Üniversitesi Mühendislik Dergisi, 6(3): 161-170, (2021).

Erişim linki (To link to this article): http://dergipark.gov.tr/humder/archive 


Mühendislik Dergisi

Araştırma Makalesi

\title{
Mono ve Multi-split Klima Sistemlerinin Ömür Boyu Maliyet Analizi
}

\author{
Emrah KARA ${ }^{1}$, Mehmet Azmi AKTACIR ${ }^{2}$, Mehmet KUŞ ${ }^{3}$ \\ ${ }^{1}$ Harran Üniversitesi, Yenilenebilir Enerji KaynaklarıABD., Şanlıurfa,emrahkara@harran.edu.tr \\ ${ }^{2}$ Harran Üniversitesi, Mühendislik Fakültesi., Makine Mühendisliği Bölümü, Şanlıurfa, aktacir@harran.edu.tr \\ ${ }^{3}$ Harran Üniversitesi, Teknik Bilimler Meslek Yüksekokulu, Şanlıurfa,mehmetkus@harran.edu.tr
}

$\ddot{O} z$

Makale Bilgisi

Bașvuru: 22/05/2021

Yayın: 30/12/2021

Anahtar Kelimeler

Enerji Tasarrufu,

Maliyet Analizi,

Multi split Klima,

Mono Split Klima

Keywords

Energy Saving,

Cost Analysis,

Multi split Air

Conditioner,

Mono Split Air

Conditioner
Giderek artan dünya nüfusu ve buna bağlı olarak sanayileşmenin de hızla büyümesiyle enerji ihtiyacına olan bağlılık günden güne artmaktadır. Bunun yanında fosil yakıtların temininin giderek zorlaşacağı ve yakın gelecekte tükeneceği tahmin edilmektedir. Bu nedenle elektrik tüketiminin azaltılması açısından cihaz seçimleri de oldukça önemli bir hâl almaktadır. Bu makalede iki farklı klima sisteminin ömür boyu maliyet analizi yöntemi ile ilk yatırım maliyetlerinin ve işletme maliyetinin en önemli maddesi olan enerji tüketimlerinin kıyaslanarak, en doğru seçimin yapılması amaçlanmıştır. Elde edilen sonuçlara göre, multi-split klimalarının mono split klimalara göre enerji tüketim oranlarının daha az olması nedeniyle işletme giderlerinde daha avantajlı olduğu belirlenmiştir. Tüm yıl kullanımı durumunda geri ödeme süresinin bir yıldan az olduğu tespit edilmiştir. Multi-split klimaların ilk yatırım bedelleri değişkenlik göstermektedir. Cihazlar alınmadan önce iyi bir pazar araştırmasının yapılması gerekir.

\section{Life Cycle Cost Analysis of Multi and Mono-split Air Conditioning Systems}

\begin{abstract}
With the increasing world population and the rapid growth of industrialization, the commitment to energy needs is increasing day by day. With the developing technology, the use of devices that need electricity consumption is increasing depending on the development levels of the countries. Therefore, device selection becomes very important in terms of reducing electricity consumption. In this article, it is aimed to make the right choice by comparing the first investment costs and energy consumption, which is the most important item of the operating cost, with the life cost analysis method of two different air conditioning systems. According to the results obtained, it has been determined that multi split air conditioner is more advantageous in operating expenses due to its lower energy consumption rate than mono split air conditioner. It has been determined that the payback period is less than one year in case of all-year use. The initial investment costs of Multi-split air conditioners vary in the market. Before devices are purchased, market research needs to be done.
\end{abstract}

\section{GİRIŞ̧ (INTRODUCTION)}

Günlük hayatta yaşanılan kapalı (mahallerde) alanlarda termal konfor şartları sağlamak için genellikle 1sıtma, soğutma ve havalandırma (HVAC) ekipmanları kullanılmaktadır. Bu ekipmanların neredeyse tamamında elektrik enerjisine ihtiyaç duyulmaktadır. Elektrik enerji üretiminin fosil yakıtlara dayalı olarak gerçekleştirildiği günümüzde bu cihazlarda enerji tüketiminin sınırlandırılması ile enerji tasarrufu sağlanabilir. Bu cihazların elektrik enerji tüketim değerlerinin sınırlandırılması ile ilgili olarak Avrupa Komisyonu 'Eko-Tasarım Direktifi' 'ni yayınlayarak gerçek çalışma standartlarını yansıtması amacıyla kapasitesi $12 \mathrm{~kW}$ 'in altındaki klimalar için performans ölçüm metotlarında sezonsal verimlilik terimini

\footnotetext{
* İletişim yazarı, e-mail: aktacir@harran.edu.tr
} 
tanımlamıştır [1]. Bütün bunların sonucu olarak yeni enerji etiketi oluşturulmuştur. Ülkemizde klimaların enerji etiketlemesine dair tebliğ 24.12.2013 tarihinde yayınlanmıştır [2]. Bu tebliğde 1sıtma sezonu için Türkiye'nin iklim haritası çıkarılarak Türkiye 3 farklı iklim bölgesine ayrılmıştır. Bu tebliğde, ülkemizde uygulanan klima etiketleme sinıflaması Avrupa'da kullanılan enerji etiketlemesiyle aynı şekilde kullanılmıştır [1]. Klimalar sezonsal verimlilik (SEER ve SCOP) değerlerine göre $\mathrm{A}+++, \mathrm{A}++, \mathrm{A}+, \mathrm{A}, \mathrm{B}$, C, D olarak sınıflandırılmaktadır. Burada kullanılan sezonsal verimlilik değerlerinin belirlenmesinde sabit bir sıcaklık değeri yerine tüm sezonda görülen sıcaklık değerleri dikkate alınarak tam ve kısmi yüklerde hesaplama yapılmaktadır. Böylece gerçek çalışma koşullarına uygun bir hesaplama yöntemi kullanılmaktadır.

ISKID verilerine göre 2017 yılında ülkemizde split klimanın iç pazarda satışı 1 milyona ulaşmış ve 1 milyon split klima da ihraç edilmiştir [3]. Özellikle split klimalar ülkemizde mahal soğutma koşullarını sağlamada en fazla kullanılan soğutma sistemi olmuştur. Buhar sıkıştırmalı soğutma çevrimine göre çalışan split klima sistemleri iç ve diş üniteden oluşmaktadır. Split klima, bir dış ünite ve bir iç ünitenin kullanılması durumunda mono-split olarak adlandırılır. Bir dış ünite birden fazla iç ünite ile kullanılması durumunda ise multi-split olarak ifade edilir. Sadece tek bir mahallin klimatize edilmesinde mono-split klima kullanılırken birden fazla mahal veya büyük alana sahip mahallerde ise multi-split klimalar tercih edilmektedir.

Klima kullanıcılarının sistem seçimlerinde genel yaklaşım ilk yatırım değerlerine göre bir kıyaslama yapılması yönündedir. Ancak, bu cihazlar satın alınmadan önce ilk yatırım maliyetlerinin yanı sıra işletme maliyetlerini de göz önüne alarak karar vermek gerekir. Bir klima cihazının ekonomik ömrü boyunca ilk yatırım maliyetinin çok üzerinde bir işletim maliyeti ortaya çıkmaktadır [4]. Dolayısıyla bu tür cihazlarının ekonomik kriterlere göre değerlendirilerek seçilmesi uygun olacaktır.

Klima sistemlerinin iç ortam ve diş ortam koşullarından etkilenmesi nedeniyle klima sistemlerinin işletme giderlerinin tespiti oldukça zor bir işlemdir. Gerçek zamanlı enerji tüketim değerlerinin olmadığı durumlarda işletme giderlerinin tespiti için çeşitli yaklaşımlar kullanılmaktadır. Bunların başında simülasyon programları yardımıyla işletme giderleri tespiti gelmektedir. Bunun dışında diğer bir yöntemde, en basit enerji tahmin tekniklerinden olan derece-gün yöntemidir. Bu yöntemde; bir mahallin enerji ihtiyacı, iç ortam sıcaklığı ile dış hava sıcaklığı arasındaki fark ile doğru orantılı olarak tahmin edilebilir [5-7]. Literatürde bu yöntemi kullanarak yapılan çeşitli çalışmalar bulunmaktadır [8-11]. Isıtma ve soğutma çalışma süresi yöntemi belirli bir zamanda (gün, ay, yıl) dış ortam ve oda sıcaklığını hesaba katarak soğuğun/sıcağın şiddetini açıklar. Ülkemizde, Meteoroloji Genel Müdürlüğü, tüm illerin uzun yıl (2007-2021) 1sıtma ve soğutma çalışma süresini kurum web sayfasından yayınlamaktadır [12]. Isıtma ve soğutma çalışma süresi için denge sıcaklıkları $15^{\circ} \mathrm{C}$ ve $22^{\circ} \mathrm{C}$ alınmıştır.

Bu çalışmada, aynı kapasiteye sahip bir multi-split klima sistemi ile mono-split klima sisteminin ömür boyu maliyet analizi yöntemini kullanılarak ekonomik analizi gerçekleştirilmiştir. Klimaların işletme giderlerinin tespitinde, ısıtma ve soğutma çalışma süre değerleri ve sezonsal performans katsayılarına göre hesaplama yapılmıştır.

\section{YÖNTEM}

Bu çalışmada Şanlıurfa ilinde 24 saat faaliyet göstermekte olan bir çağrı merkezinde kullanılmak üzere; iki adet $9000 \mathrm{Btu} / \mathrm{h}$ ve bir adet $12000 \mathrm{Btu} / \mathrm{h}$ olmak üzere toplam 3 adet split klima dikkate alınmıştır. Burada kullanılacak klima sistemleri multi ve mono-split sistemler olup şekil 1'de şematik olarak gösterilmiştir.

Multı-split klima veya mono-split klima sistemleri için 4 farklı üreticiden fiyat teklifi alınmıştır. İlk yatırım maliyetinin hesaplanabilmesi için $\mathrm{A}, \mathrm{B}, \mathrm{C}$ ve $\mathrm{D}$ markalarından mono ve multi-split klima sistemlerine ait $9000 \mathrm{Btu} / \mathrm{h}$ kapasiteli klima ile $12000 \mathrm{Btu} / \mathrm{h}$ kapasiteli klimalar için fiyat teklifleri alınmıştır.Tablo1'de iki sisteme ait ilk yatırım maliyetleri ile ortalama değeri sunulmuştur.

Split klima sistemleri fiyatlarında marka ve piyasanın rekabet koşullarına göre farklılıklar görülmektedir. Hesaplamalarda ilk yatırım maliyeti olarak 4 markadan alınan fiyatların ortalaması alınmıştır. Buna göre, Mono-split klimanın ilk yatırım maliyeti $13.607,50$ TL ve Multi-split klimanın ilk yatırım maliyeti 
14.860,00 TL olarak belirlenmiştir. Multi-split klimanın ilk yatırım maliyetleri mono-splite göre \%9 daha fazladir.

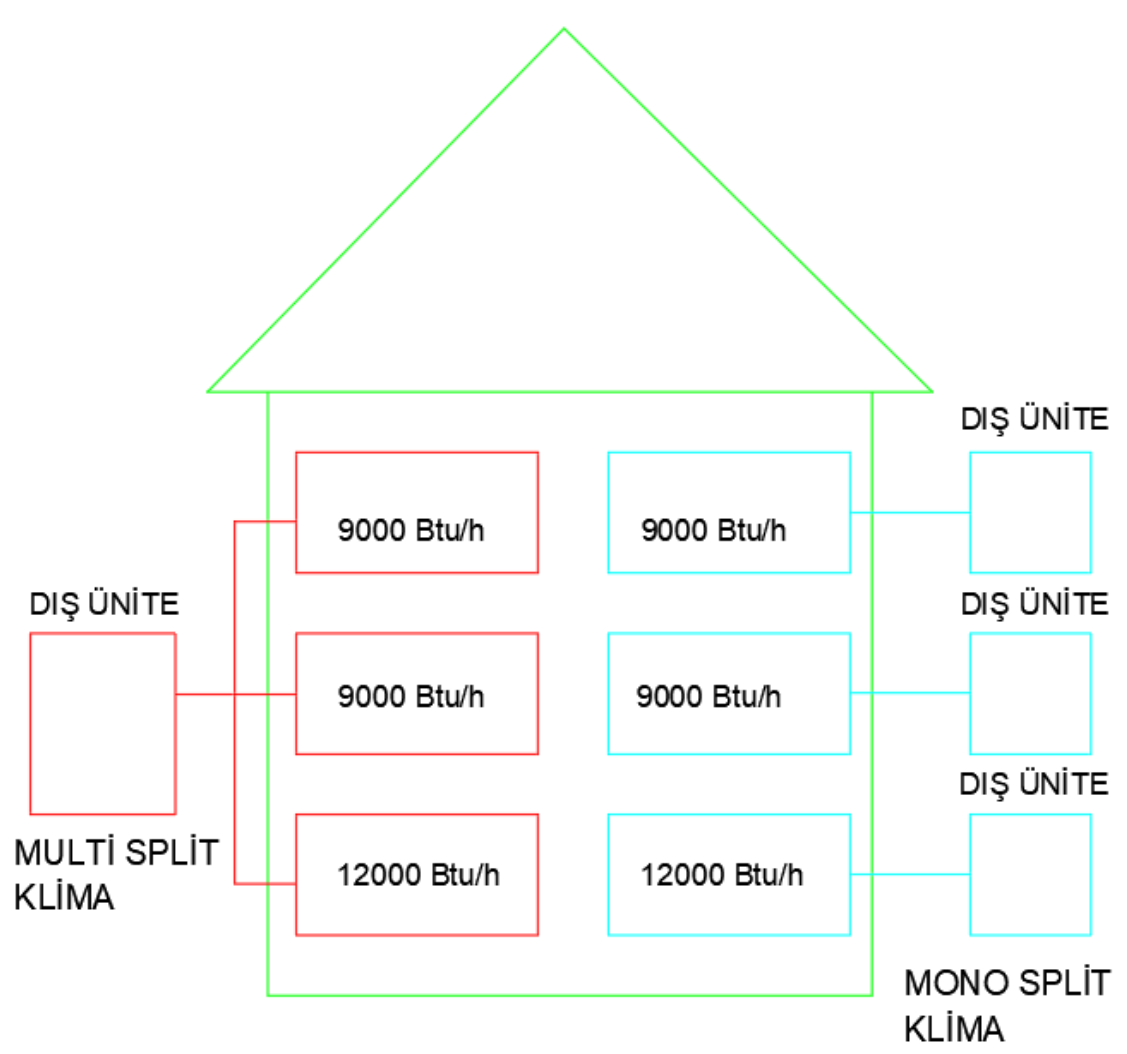

Şekil 1. Mahalde kullanılan klima sistemlerinin şematik gösterimi

Tablo 1. Mono split Klima ve Multi split klima sistemlerine ait piyasa fiyat araştırma tablosu

\begin{tabular}{|c|c|c|c|c|}
\hline \multirow{2}{*}{ Marka } & \multicolumn{3}{|c|}{ Mono Split Klima } & Multi Split Klima \\
\cline { 2 - 5 } & $\begin{array}{c}\mathbf{9 0 0 0} \text { Btu/h } \\
\text { Fiyatı (TL) }\end{array}$ & $\begin{array}{c}\mathbf{9 0 0 0} \text { Btu/h } \\
\text { Fiyatı (TL) }\end{array}$ & $\begin{array}{c}\mathbf{1 2 0 0 0} \text { Btu/h } \\
\text { Fiyatı (TL) }\end{array}$ & $\begin{array}{c}\mathbf{9 0 0 0} \text { Btu/h +9000 Btu/h+12000 } \\
\text { Btu/h) Fiyatı (TL) }\end{array}$ \\
\hline A & $5.150,00$ & $5.150,00$ & $5.700,00$ & $23.800,00$ \\
\hline B & $4.565,00$ & $4.565,00$ & $4.500,00$ & $16.000,00$ \\
\hline D & $4.000,00$ & $4.000,00$ & $4.400,00$ & $9.500,00$ \\
\hline Ortalama & $4.000,00$ & $4.000,00$ & $4.400,00$ & $10.140,00$ \\
\hline Toplam Maliyet & $4.428,75$ & $4.428,75$ & $4.750,00$ & $14.860,00$ \\
\hline
\end{tabular}


$\mathrm{Bu}$ çalışmada, sistemin 1sıtma ve soğutma sezonu boyunca enerji tüketimini bulmak için 1sıtma ve soğutma çalışma süresi değerleri ile cihazın enerji tüketim değeri çarpılmıştır. Hesaplamada hem 1sıtma hem de soğutma sezonu boyunca cihazların çalıştığı kabul edilmiştir. Enerji tüketim değerleri enerji maliyet değeri ile çarpılarak sistemin işletme maliyetleri bulunmuştur.

$\mathrm{Bu}$ çalışmada, yıllık periyodik bakım maliyetleri multi-split klima sistemi için $250 \mathrm{TL}$ ve mono-split klima sistemi için ise 350 TL olarak alınmıştır.

Tablo 2'de 2011 ile 2020 arasında Şanlıurfa ilinin 10 yıllık 1sıtma ve soğutma ihtiyacı olan gün sayısını vermektedir [12]. Şanlıurfa için 2020 yılında 1sıtma gün sayısı 145 gün ve soğutma gün sayısı 168 gün olarak gerçekleşmiştir. Bu çalışmada hesaplamalarda Şanlıurfa ilinin 1sıtma ve soğutma ihtiyacı için 10 yıllık ortalama değerleri kullanılmıştır.

Tablo 2. Şanlıurfa ilinin Isıtma ve Soğutmaya İhtiyaç Duyulan Gün Sayısı

\begin{tabular}{|c|c|c|}
\hline Yıl & $\begin{array}{c}\text { Isıtma Gün Dereceleri (HDD) } \\
\text { [Gün] }\end{array}$ & $\begin{array}{c}\text { Soğutma Gün Dereceleri (CDD) } \\
\text { [Gün] }\end{array}$ \\
\hline $\mathbf{2 0 1 1}$ & 156 & 130 \\
\hline $\mathbf{2 0 1 2}$ & 143 & 159 \\
\hline $\mathbf{2 0 1 3}$ & 137 & 152 \\
\hline $\mathbf{2 0 1 4}$ & 139 & 156 \\
\hline $\mathbf{2 0 1 5}$ & 154 & 159 \\
\hline $\mathbf{2 0 1 6}$ & 127 & 166 \\
\hline $\mathbf{2 0 1 7}$ & 141 & 148 \\
\hline $\mathbf{2 0 1 8}$ & 127 & 165 \\
\hline $\mathbf{2 0 1 9}$ & 154 & 168 \\
\hline $\mathbf{2 0 2 0}$ & 145 & 156.4 \\
\hline Ortalama & 142,3 & \\
\hline
\end{tabular}

İşletme maliyetinin hesaplanması sırasında göz önünde bulundurulması gereken en önemli parametre, cihazın enerji tüketim miktarıdır. Bu çalışmada incelenen sistemlere ait enerji tüketimleri cihazların teknik dokümanlarından alınmıştır.

Tablo 3'te Mono-split klima için Tablo 4'te Multi-split klima için enerji tüketim değerleri sunulmuştur.

$\mathrm{Bu}$ çalışmada ekonomik analizleri yapılacak olan multi ve mono-split klima sistemleri arasında ömür boyu maliyet analizi yapmak için şimdiki değer yöntemi kullanılacaktır. Faiz oranı (I) ve Enflasyon oranı (g) olmak üzere; İskonto oranı (I) eşitlik 1 ile bulunur [4]. Eşitlik 2 ile şimdiki değer faktörü (PWF) hesaplanır [4]. Bu eşitlikte $\mathrm{N}$ cihazın ekonomik ömrünü göstermektedir.

$\mathrm{g}<\mathrm{I}$ ise;

$$
\dot{\mathrm{I}}=\frac{(\boldsymbol{I}-\boldsymbol{g})}{(1+g)}
$$




$$
\mathrm{PWF}=\frac{(\mathbf{1}+\mathrm{i})^{N}-\mathbf{1}}{\mathrm{i}(\mathbf{1}+\mathrm{I})^{N}}
$$

$\mathrm{g}>\mathrm{I}$ ise;

$$
\begin{aligned}
& \dot{\mathrm{I}}=\frac{(g-I)}{(1+g)} \\
& \mathrm{PWF}=\left[\frac{1}{(\dot{\mathrm{I}}+1)}\right]
\end{aligned}
$$

Sistemin şimdiki değeri (PWC) eşitlik 5 ile bulunur [4]. Bu eşitlikte ilk yatırım maliyeti (IC) ve İşletme maliyeti (OC) göstermektedir.

$\mathrm{PWC}=\mathrm{IC}+(\mathrm{OC} * \mathrm{PWF})$

Bu çalışmada, Merkez Bankasından Aralık 2020 tarihinde alınan verilere göre; enflasyon oranı \%14.03 ve faiz oranı \%17 olarak hesaplamaya dâhil edilmiştir. Ayrıca, 2020 yılı güncel elektrik maliyeti 0.742

\begin{tabular}{|c|c|c|c|}
\hline Marka & Kapasite & $\begin{array}{c}\text { Soğutma Sezonu için Enerji } \\
\text { Tüketimi }(\mathbf{k W})\end{array}$ & $\begin{array}{c}\text { Isıtma Sezonu için Enerji } \\
\text { Tüketimi }(\mathbf{k W})\end{array}$ \\
\hline \multirow{2}{*}{ A } & $9000 \mathrm{Btu} / \mathrm{h}$ & 0,71 & 0,69 \\
\hline & $12000 \mathrm{Btu} / \mathrm{h}$ & 0,91 & 0,93 \\
\hline \multirow{2}{*}{ B } & $9000 \mathrm{Btu} / \mathrm{h}$ & 1,24 & 1,20 \\
\hline & $12000 \mathrm{Btu} / \mathrm{h}$ & 1,30 & 1,19 \\
\hline \multirow{2}{*}{$\mathbf{C}$} & $9000 \mathrm{Btu} / \mathrm{h}$ & 0,78 & 0,87 \\
\hline & $12000 \mathrm{Btu} / \mathrm{h}$ & 1,35 & 1,12 \\
\hline \multirow{2}{*}{ D } & $9000 \mathrm{Btu} / \mathrm{h}$ & 0,70 & 0,80 \\
\hline & $12000 \mathrm{Btu} / \mathrm{h}$ & 1,08 & 1,05 \\
\hline \multicolumn{2}{|c|}{$9000 \mathrm{Btu} / \mathrm{h}$ için ortalama } & 0,86 & 0,89 \\
\hline \multicolumn{2}{|c|}{$12000 \mathrm{Btu} / \mathrm{h}$ için ortalama } & 1,16 & 1,07 \\
\hline
\end{tabular}
$\mathrm{TL} / \mathrm{kWh}$ ve her iki klima sisteminin çalışma ömrü 15 yıl olarak alınmıştır.

Tablo 3. Farklı marka Mono split klimaların enerji tüketim değerleri 
Tablo 4. Farklı marka Multi-split klimanın enerji tüketim değerleri

\begin{tabular}{|c|c|c|c|}
\hline Marka & Kapasite & $\begin{array}{l}\text { Soğutma Sezonu İçin } \\
\text { Enerji Tüketimi }(\mathbf{k W})\end{array}$ & $\begin{array}{l}\text { Isitma Sezonu için Enerji } \\
\text { Tüketimi (kW) }\end{array}$ \\
\hline $\mathbf{A}$ & $\begin{array}{l}(9000+9000+12000) \\
\text { Btu/h }\end{array}$ & 2,16 & 2,26 \\
\hline B & $\begin{array}{l}(9000+9000+12000) \\
\text { Btu/h }\end{array}$ & 2,63 & 2,27 \\
\hline C & $\begin{array}{l}(9000+9000+12000) \\
\text { Btu/h }\end{array}$ & 2,47 & 2,27 \\
\hline D & $\begin{array}{l}(9000+9000+12000) \\
\text { Btu/h }\end{array}$ & 3,01 & 2,79 \\
\hline \multicolumn{2}{|c|}{$\begin{array}{l}\text { Ortalama }(9000+9000+12000) \\
\text { Btu/h }\end{array}$} & 2,57 & 2,40 \\
\hline
\end{tabular}

\section{3. ÖMÜRBOYU MALIYET HESABI VE DEĞERLENDİRME}

Bu çalışmada multi ve mono-split klima sistemlerinin enerji tüketim değerleri, 1sıttma sezonu için Tablo 5 ve soğutma sezonu için Tablo 6'da verilmiştir. Sezonluk enerji tüketimi; 1sıtma ve soğutma çalışma süreleri, klimanın günlük çalışma saati ve klimanın saatlik enerji tüketim değerlerinin çarpılmasıyla bulunmuştur.

Tablo 5. Isıtma sezonu için cihazların toplam enerji tüketim değeri

\begin{tabular}{|c|c|c|c|c|}
\hline Cihaz & $\begin{array}{c}\text { Enerji } \\
\text { Tüketimi } \\
\mathbf{( k W )}\end{array}$ & $\begin{array}{c}\text { Çalşsma } \\
\text { Saati (h) }\end{array}$ & $\begin{array}{c}\text { Isıtma } \\
\text { Çalışma } \\
\text { Süresi }\end{array}$ & $\begin{array}{c}\text { Tüketim } \\
\text { (kWh/ssıtma sezonu) }\end{array}$ \\
\hline Mono split 9000 Btu/h & 0,89 & 24 & 142,3 & 3039,528 \\
\hline Mono split 12000 Btu/h & 1,07 & 24 & 142,3 & 3654,264 \\
\hline Mono split toplam & & & 142,3 & 8190,503 \\
\hline $\mathbf{9 0 0 0 + 9 0 0 0 + 1 2 0 0 0 )}$ Btu/h & & 24 & & \\
\hline Multi split & 2,40 & & & \\
\hline
\end{tabular}


Tablo 6. Soğutma sezonu için cihazların toplam enerji tüketim değeri

\begin{tabular}{|c|c|c|c|c|}
\hline Cihaz & $\begin{array}{c}\text { Enerji } \\
\text { Tüketimi } \\
\mathbf{( k W )}\end{array}$ & $\begin{array}{c}\text { Çalışma } \\
\text { saati (h) }\end{array}$ & $\begin{array}{c}\text { Soğutma } \\
\text { Çalışma } \\
\text { Süresi }\end{array}$ & $\begin{array}{c}\text { Tüketim } \\
\mathbf{( k W h / s o g ̆ u t m a ~ s e z o n u ) ~}\end{array}$ \\
\hline Mono split 9000 Btu/h & 0,86 & 24 & 156,4 & 3228,10 \\
\hline Mono split 12000 Btu/h & 1,16 & 24 & 156,4 & 4354,18 \\
\hline $\begin{array}{c}\text { Mono split toplam } \\
\mathbf{9 0 0 0 + 9 0 0 0 + 1 2 0 0 0 )} \text { Btu/h }\end{array}$ & 2,57 & 24 & 156,4 & 10810,37 \\
\hline $\begin{array}{c}\text { Multi split } \\
\mathbf{9 0 0 0 + 9 0 0 0 + 1 2 0 0 0 )} \mathbf{B t u} / \mathbf{h}\end{array}$ & $2,4632,68$ \\
\hline
\end{tabular}

Tablo 5 ve 6'dan görüldüğü gibi, Mono-split klimanın 1sıtma sezonu için toplam enerji tüketimi 9733,32 $\mathrm{kWh}$ ve soğutma sezonu için toplam enerji tüketimi $10810,37 \mathrm{kWh}$ olarak bulunmuştur. Bu değerler, Multi-split klima için 8190,503 kWh ve 9632,68 kWh'dir. Mono-split klima sisteminin enerji tüketimi multi-split klima sistemine göre 1sıtma için $\% 15,85$ ve soğutma için $\% 12$ daha fazla olmuştur. Hesaplanan sezonluk enerji tüketim değerleri, elektrik birim fiyatı ile çarpılarak sezonluk enerji tüketim bedelleri elde edilmiştir. Bu çalışmada klimaların; soğutma sezonu, 1sıtma sezonu ve yıl boyunca kullanım durumları dikkate alınarak işletme giderleri hesaplanmıştır. Tablo 7'de cihazların işletme maliyetleri verilmiştir.

Tablo 7. Çalışma dönemine göre klimaların yıllık işletme maliyetleri

\begin{tabular}{|c|c|c|c|c|c|}
\hline \multirow{2}{*}{$\begin{array}{c}\text { Çalışma } \\
\text { dönemi }\end{array}$} & Cihaz & $\begin{array}{c}\text { Tüketim } \\
\mathbf{( k W h / y ı l )}\end{array}$ & $\begin{array}{c}\text { Elektrik } \\
\text { Fiyatı } \\
\mathbf{( T L / k W h )}\end{array}$ & $\begin{array}{c}\text { İşletme } \\
\text { Maliyeti (TL) }\end{array}$ & $\begin{array}{c}\text { Tasarruf } \\
\text { Miktarı }\end{array}$ \\
\hline \multirow{2}{*}{$\begin{array}{c}\text { Isıtma } \\
\text { Sezonu }\end{array}$} & Mono split sistem & 9733,32 & 0,742 & $7.222,12$ & - \\
\cline { 2 - 6 } & Multi split sistem & 8190,5034 & 0,742 & $6.077,35$ & $\% 18$ \\
\hline \multirow{2}{*}{$\begin{array}{c}\text { Soğutma } \\
\text { Sezonu }\end{array}$} & Mono split sistem & 10810,37 & 0,742 & $8.021,29$ & - \\
\cline { 2 - 6 } & Multi split sistem & 9632,68 & 0,742 & $7.147,45$ & $\% 11$ \\
\hline \multirow{2}{*}{ Yıllık } & Mono split sistem & 20400,05 & 0,742 & $15.593,42$ & - \\
\cline { 2 - 6 } & Multi split sistem & 17702,32 & 0,742 & $13.135,12$ & $\% 13$ \\
\hline
\end{tabular}


Tablo 7'den görüldüğü gibi multi-split klimanın yıllık işletme maliyeti (1sıtma ve soğutma sezonu toplamı) 13.474,8 TL olarak hesaplanmıştır. Mono-split klimanın yıllık işletme maliyeti ise multi-split klimanın işletme maliyetinden \%15 daha büyük yani $15.593,42 \mathrm{TL}$ olarak hesaplanmıştır. Isıtma sezonunda klima sistemlerinin işletme maliyeti multi sistemde \%18 ve soğutma sezonunda klima sistemlerinin işletme maliyeti multi sistemde $\% 11$ daha tasarruflu elde edilmiştir.

Tablo 8'de verilen maliyet değerlerine göre mono ve multi-split klima sistemlerinin 15 yıllık çalışma ömrü için ömür boyu maliyet analizi yapılmıştır. Analizde klima sistemlerinin sadece 1sıtma sezonunda, sadece soğutma sezonunda ve son olarak hem 1sıtma hem de soğutma sezonunda çalıştığı kabul edilmiştir.

Tablo 8. Klimaların işletme, ilk yatırım ve bakım maliyet tablosu

\begin{tabular}{|l|c|c|c|c|}
\hline & \multirow{2}{*}{$\begin{array}{c}\text { Illk Yatırım } \\
\text { Maliyetleri } \\
\text { (TL) }\end{array}$} & \multicolumn{2}{|c|}{ Işsletme ve bakım Maliyetleri (TL) } \\
\cline { 3 - 5 } & & Isıtma Sezonu & Soğutma Sezonu & Yıllık \\
\hline Mono Split Klima & $13.607,50$ & $7.572,12$ & $8.371,29$ & $15.943,41$ \\
\hline Multi Split Klima & $14.860,00$ & $6.327,37$ & $7.397,45$ & $13.724,82$ \\
\hline
\end{tabular}

Şekil 2'de klima sistemlerinin ömür boyu maliyetlerinin şimdiki değeri ve geri ödeme süresi görülmektedir.

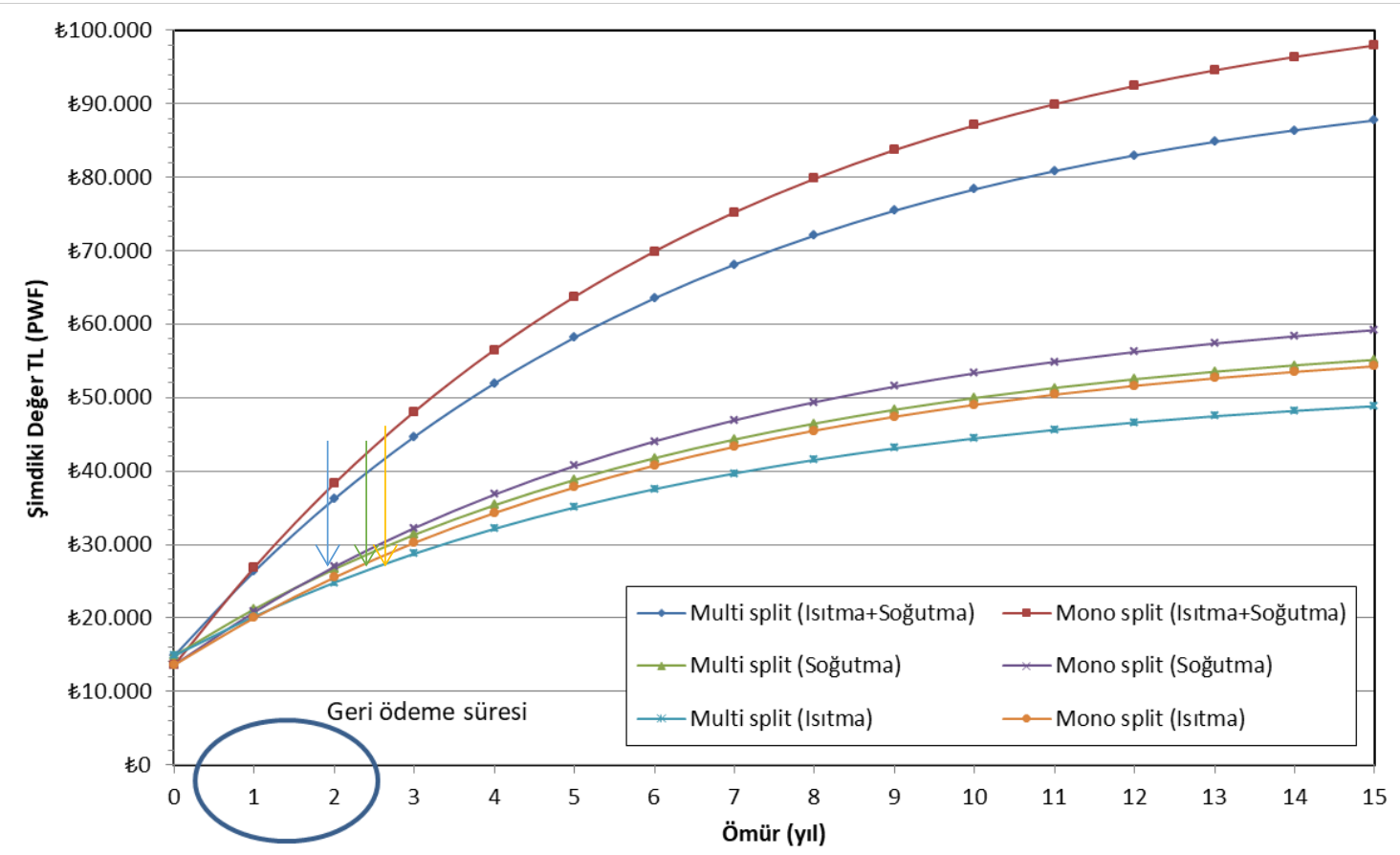

Şekil 2. Klima cihazlarının ömür boyu maliyetlerinin şimdiki değerleri 
Klima sistemlerinin yıl boyu kullanımı durumunda; klima sisteminin 15 yıllık çalışma ömrü sonunda multi-split klimanın şimdiki değeri (PWC) 88.262,23 TL iken mono-split klimanın şimdiki değeri (PWC) 98.550,62 TL'dir. Bu durumda yatırım maliyetinin geri ödemesi 0.8 yıl (yaklaşık 9 ay) olmaktadır. Bu sistemin soğutma sezonunda kullanımı durumunda; klima sisteminin 15 yıllık çalışma ömrü sonunda multi-split klimanın şimdiki değeri (PWC) 55.156,63 TL iken mono split klimanın şimdiki değeri (PWC) 59.209,04 TL olup bu yatırım maliyetinin geri ödeme süresi 1.86 yıl (yaklaşık 22 ay) olmaktadır. Bu sistemin 1sıtma sezonunda kullanımı durumunda; klima sisteminin 15 yıllık çalışma ömrü sonunda multisplit klimanın şimdiki değeri (PWC) 49.327,44 TL iken mono-split klimanın şimdiki değeri (PWC) 54.855,66 TL olup bu yatırım maliyetinin geri ödeme süresi 1.43 yıl (yaklaşık 17 ay) olmaktadır.

\section{SONUÇLAR VE ÖNERILER (CONCLUSIONS AND RECOMMENDATIONS)}

Bu çalışmada, 24 saat kesintisiz çalışan bir ticari binada mono-split klima kullanılmaktadır. Bu sisteme alternatif olarak aynı kapasitede multi-split klimanın kullanılması durumunda ömür boyu maliyet analizi gerçekleştirilmiştir.

Elde edilen sonuçlara göre;

- Multi-split klimaların ilk yatırım bedelleri değişkenlik göstermektedir. Pazarda, ithal ürünlere nazaran yerli marka ürünlerde daha avantajlı bir fiyat sunulmaktadır. Cihazlar alınmadan önce iyi bir pazar araştırmasının yapılması gerekir.

- Multi-split klimaların enerji tüketimleri ve işletme maliyetleri mono split klimalara göre (\%11-18) daha düşüktür.

- Mono-split klima yerine Multi-split klima tercih edildiği zaman sistemin geri ödeme süresi 2 yıldan az olmaktadır. Eğer, klima sistemi hem ısıtma hem de soğutma sezonunda kullanılıyorsa yatırım maliyetinin geri ödeme süresi bir yıldan az olmaktadır.

- Klima sistemlerinin ekonomik ömürleri 15 yıl kabul edildiğinde, sistemin geri ödeme süreleri (ömrünün \%5-12 arasında) 2 yıldan az olduğundan ekonomik açıdan mükemmel bir yatırım olarak değerlendirilir.

\section{ÇIKAR ÇATIŞMASI (CONFLICT OF INTEREST)}

Makale yazarları aralarında herhangi bir çıkar çatışması olmadığını beyan ederler.

\section{KAYNAKLAR (REFERENCES)}

[1] A. Yakut, Sezonsal verimlilik ve klimalarda yeni enerji etiketi. TTMD Isıtma, Soğutma, Havalandırma, Klima, Yangın ve Sihhi Tesisat Dergisi, 91:2 (2014) 23-30.

[2] Klimaların Enerji Etiketlemesine Dair Tebliğ, Resmi Gazete, 24 Aralık 2013, Sayı 28861.

[3] İklimlendirme Soğutma Klima İmalatçıları Derneği İSKID, Klima ve soğutma istatistikleri 2017. https://iskid.org.tr/istatistikler-ve-raporlar/ (Erişim 15.05.2021).

[4] M.A. Aktacir, O. Büyükalaca, T. Yilmaz, Life-cycle cost analysis for constant-air-volume and variable-air-volume air-conditioning systems, Applied Energy 83:6 (2006), 606-627.

[5] H. Bulut, O. Büyükalaca, T. Yılmaz, Türkiye için isıtma ve soğutma derece-gün bölgeleri, ULIBTK'07 16. Ulusal Isı Bilimi ve Tekniği Kongresi Bildiriler Kitabı, Kayseri, 2007. 
[6] O. Büyükalaca, H. Bulut, T. Y1lmaz, Analysis of variable-base heating and cooling degree-days for Turkey. Applied Energy, 69:4, (2001) 269-283.

[7] O. Büyükalaca, H. Bulut, T. Yılmaz, Türkiye'nin bazı illeri için derece-gün değerleri. 12. Ulusal Isı Bilimi ve Tekniği Kongresi Bildiriler Kitabı, Cilt 1, sayfa 107-112, Sakarya, 2000.

[8] O. Kon ve B. Yüksel, Kamu binalarının isıtma yüküne göre dış duvarlarının optimum yalıtım kalınlıkları ve enerji tüketimleri. Balıkesir Üniversitesi Fen Bilimleri Enstitüsü Dergisi, 15:1 (2013), $30-47$.

[9] A. Dombaycı, H. Bayrakçı, A. Özgür, Konutlarda soğutma enerjisi tüketiminin farklı baz sıcaklıkları için derece gün yöntemiyle tahmini. Süleyman Demirel Üniversitesi Fen Bilimleri Enstitüsü Dergisi, 13:3 (2014), 311-314.

[10] S. Koçak,C. Şaşmaz, İ. Atmaca, Farklı derece-gün bölgeleri için TS825'e uygun olarak yalıtılan bir alışveriş merkezinin teknik ve ekonomik yönden incelenmesi. Tesisat Mühendisliği dergisi, 128:2 (2012), 76-88.

[11] M. Özel, K. Pihtili, Determination of optimum insulation thickness by using heating and cooling degree-day values. Journal of Engineering and Natural Sciences Sigma, $26: 3$ (2008) 191-197.

[12] Meteoroloji Genel Müdürlüğü Isitma ve Soğutma Gün Dereceleri https://mgm.gov.tr/veridegerlendirme/gun-derece.aspx (Erişim 15.05.2021). 